\author{
Karolina Majkowska \\ Maria Curie-Skłodowska University \\ ul. Sowińskiego 17 \\ 20-040 Lublin, Poland
}

\title{
Neobaroque and the experience of America in The Brief Wondrous Life of Oscar Wao by Junot Díaz ${ }^{1}$
}

\begin{abstract}
The article discusses the immigrant experience of America in The Brief Wondrous Life of Oscar Wao by Junot Díaz and analyses it with the use of the neobaroque esthetics. The paper seeks to present neobaroque elements present in the text, such as hybridity and the tension between the center and the peripheries to show that neobaroque poetics can be successfully employed to talk about the experience of exile, the migrant condition and the search for identity. Keywords: immigrant experience; hybridity; Junot Díaz; neobaroque; The Brief Wondrous Life of Oscar Wao
\end{abstract}

The concepts often discussed in relation with ethnic identities include hybridity, biculturalism, cultural transition, and hyphenated identity a term devised by Gustavo Pérez-Firmat. All of them suggest a combination of different elements belonging to the culture of home and of the receiving country. John Riofrio in his article "Situating

\footnotetext{
${ }^{1}$ The analysis of Junot Díaz's text is part of a bigger research project - a doctoral dissertation.
} 
Neobaroque and the experience of America in The Brief Wondrous.. 127

Latin American masculinity: Immigration, empathy and emasculation in Junot Díaz's Drown" focuses on the issue of identity and analyzes it in the context of immigration. He claims that "immigration produces categorical shifts in how we experience and also understand ourselves as people." Stuart Hall adds that identity "is never complete, always in process, and always constituted within, not outside, representation"3 and since it is a matter of becoming, it undergoes constant transformations ${ }^{4}$. Hall devotes special attention to Caribbean identities and places them in a dialogic relation between two axes, or vectors: "similarity and continuity; and the vector of difference and rupture." $\mathrm{He}$ sees the Caribbean at the margin, belonging to "the underdeveloped, the periphery, the 'Other' . . . at the outer edge, the 'rim', of the metropolitan world - always 'South' to someone else's $E l$ Norte." Predictably, this peripheral position concerns also the Caribbean migrants in the United States.

What prevails in the discussions of immigrants' experience is the sense of hybridity, unbelonging, suspension between the culture of origin and the new culture, and the continuous search for the new hyphenated identity. Krumrey observes that migrants have no destination, many are nomads, and they "reject the established borders and frontiers between and within America and embrace instead the intermediate, indeterminate space between the cultures."7 They are never fully American, and they do not belong to the culture of origin either, thus they inhabit the space in-between.

In his analysis of contemporary diasporas ${ }^{8}$, Igor Maver suggests that the binary constructions employed to discuss the relation between Us and the Other are no longer valid, and it has become difficult to tell

\footnotetext{
${ }^{2}$ Riofrio 2008: 23.

${ }^{3}$ Hall 1990: 222.

${ }^{4}$ Hall 1990: 225

${ }^{5}$ Hall 1990: 226-227.

${ }^{6}$ Hall 1990: 228

${ }^{7}$ Krumrey 2010: 37-38.

${ }^{8}$ The Dominican migration to the United States can be treated as a diaspora.
} 
one from the other ${ }^{9}$. Therefore there exists a need to introduce new tools that would embrace the complexity of the new identities and experiences; I would argue that one of such tools is neobaroque. Consequently, this paper seeks to discuss the immigrant experience of America with the use of the neobaroque paradigm. This essay's argument will develop in three steps. First, the article will explain the neobaroque poetics; then it will focus on the neobaroque elements in The Brief Wondrous Life of Oscar Wao by Junot Díaz; and finally it will demonstrate how the employment of neobaroque contributes to the articulation of the migrants' experience of America.

Neo-baroque is the return of the Baroque, "a period marked by contradictory feelings of novelty and belatedness," $" 10$ yet not as a historical phenomenon, but as certain aesthetics. Angela Ndalianis in her study of contemporary entertainment claims that neobaroque esthetics permeates the contemporary mainstream culture ${ }^{11}$. It has been employed by different writers, including postcolonial theorists of Latin America and the Caribbean, as well as by contemporary U.S. Latino/a visual artists ${ }^{12}$.

Neobaroque, however, is not only an esthetic phenomenon, since it also has a political dimension. According to Angela Ndalianis, it is a strategy focusing on the minor and the unrepresented and whose aim is to challenge the ideology of the dominant culture, as well as to question the issue of identity, gender and reality ${ }^{13}$. Egginton supports this view and emphasizes neo-baroque's peripheral origin and its attempt to "undermine traditional colonial power structures." "Also Monika Kaup in her discussion of this neobaroque's aspect observes that political instability and violence translates into cultural, artistic and literary expressions. Moreover, she argues that neobaroque in the American republics became a "key, symptomatic expression of the

\footnotetext{
${ }^{9}$ Maver 2009: x.

${ }^{10}$ Kaup 2012: 5.

${ }^{11}$ Ndalianis 2004: 5.

${ }^{12}$ Kaup 2012: 20.

${ }^{13}$ Ndalianis 2004: 12.

${ }^{14}$ Egginton 2010: 128.
} 
Neobaroque and the experience of America in The Brief Wondrous.. 129

reigning social and political situation of crisis and catastrophe" and a tool suitable to express "discontinuity, political disillusionment, conflict between state authoritarianism and popular resistance."15

The political dimension of neobaroque manifests itself, for instance, in the tension between the center and the periphery. This is stressed by, among others, William Egginton who observes a certain dynamics, a tension between two strategies identified by him in the Spanish baroque as "a centrifugal versus a centripetal force, a major versus a minor strategy, a molar versus a molecular vector." 16

Major strategy assumes "the existence of a veil of appearances, and then suggest[s] the possibility of a space opening just beyond those appearances where truth resides." ${ }^{, 17}$ In other words, it lures the viewer into believing that whatever they see refers to some universal truth hidden behind the veil. Major strategy "is to assume that the coherence of the image is in a representative relation to something that, itself unknown, grounds that relation." Minor strategy, in turn,

does not merely ride out the 'lines of flight' linking the imago's coherence to its dissolution, its bursting onto the shores of terra incognita; rather, the minor strategy treats those limits as ends in themselves, and thereby cuts off the relations constitutive of representation ${ }^{18}$.

According to Egginton, minor strategy frequently employs the elements of the major strategy, yet they are ridiculed or taken to extremes ${ }^{19}$. Minor strategy would point to representation, to the seams that the major strategy is trying to hide. It will, therefore, emphasize the construction of the text, for instance through pointing to its frames.

This tension between the center and the peripheries, and consequently between the minor and major strategy, points to another important feature of neobaroque that is in-betweenness, the third quality, or the third space. According to José Lezama Lima and Alejo Carpentier, New World artists used the colonizer's art to express their

\footnotetext{
${ }^{15}$ Kaup 2012: 122.

${ }^{16}$ Egginton 2010: 71

${ }^{17}$ Egginton 2010: 3.

${ }^{18}$ Egginton 2010: 75.

${ }^{19}$ Egginton 2010: 76.
} 
own thoughts, and hence the baroque became the "instrument not of the Counter-Reformation but of contraconquista (counterconquest)." ${ }^{20}$ César Salgado depicted this process as "the survival of Otherness piggybacking on the unsuspecting signs of Empire."21 The encounter between the two cultures: the imperial and the native, or the culture of the colonizer and the colonized, on the one hand epitomizes the tension between the center and the periphery, on the other emphasizes the emergence of a third culture.

It may be concluded, therefore, that neobaroque - a hybrid that originated in the peripheries - occupies the space in-between and gives voice to the underrepresented, thus it parallels hybrid identities and, consequently, the immigrant experience of America. The experience of America and the immigrant identity are liquid and so is neobaroque; it focuses on the process, on becoming, and not on the final effect. Therefore it seems to be a useful tool to explore the experiences of the immigrants.

The text chosen for the analysis in this article is Junot Díaz's The Brief Wondrous Life of Oscar Wao, the winner of the 2008 Pulitzer Prize. The novel tells a fragmented story of Oscar, a Dominican kid living in New Jersey, and it also recounts the lives of Oscar's family and friends. The narrator guides the reader through the Dominican Republic of the 1940s and the contemporary America, and therefore provides insight into the histories and cultures of both countries. The novel discuses Oscar de León's experience of America focusing on the life of a boy who does not belong to either of the two cultures, who seeks acceptance, and who tries to redefine his identity. His and his relatives' struggles and experiences are presented directly in the text, but they are also intensified by the employment of neobaroque. The elements chosen for the analysis in this article include the presence of minor strategy, the tension between the center and the peripheries, and hybridity. It should be noted, however, that the

\footnotetext{
${ }^{20}$ Kaup 2012: 5.

${ }^{21}$ Salgado 1999: 324.
} 
selected examples do not exhaust the discussed issue; their role is to suggest possible analytical directions.

If the world presented in the novel is considered a framed structure, then each time the narrator addresses the reader or the characters in the novel, he points to the text's frames and pierces them. This, in turn, emphasizes the fictionality of the text and directs the reader's attention towards the neobaroque notion of representation. The narrator addresses the readers on multiple occasions, for instance when he discusses the history of the Dominican Republic in the following way: "You didn't know we were occupied twice in the twentieth century? Don't worry, when you have kids they won't know the U.S. occupied Iraq either." 22 Another example may be Yunior's comment on the political situation in the Dominican Republic:

It's true. The Gangster's wife was - drumroll, please - Trujillo's fucking sister!

Did you really think some street punk from Samaná was going to reach the upper echelons of the Trujillato on hard work alone? Negro, please - this ain't a fucking comic book! (BWLOW 138)

As far as addressing other characters in the novel is concerned, one may focus on the description of Beli's, Oscar's mother's, behavior narrated in the following way: "I wish I could say different but I've got it right here on tape. La Inca told you you had to leave the country and you laughed" (BWLOW 160).

The focus on the superficiality of the text, in turn, is probably best visible in the remarks the narrator makes about the writing process. When the narrator recalls Beli's youth, he mentions Samaná. The footnote, however, contains the following explanation:

In my first draft, Samaná was actually Jarabacoa, but then my girl Leonie, resident expert in all things Domo, pointed out that there are no beaches in Jarabacoa. Beautiful rivers but no beaches. Leonie was also the one who informed me that the perrito (see first paragraphs of chapter one, "GhettoNerd at the End of the World") wasn't popularized until the late eighties, early nineties, but that was one detail I couldn't change, just liked the image too much. Forgive me, historians of popular dance, forgive me! (BWLOW 132)

${ }^{22}$ Díaz, The Brief Wondrous Life of Oscar Wao (New York: Riverhead Books, 2007), 19. Hereafter cited in the text as $B W L O W$. 
The above-mentioned examples illustrate how the text points to the frames to highlight its fictionality, hence employing the minor strategy. Moreover, it sanctions the neobaroque reading of the novel. The complexity of the neobaroque esthetics invites different analytical approaches and focal points that examine the migrant experience.

The discussion of the migrant's experience of America cannot disregard the tension between the center and the peripheries. The analysis may adopt different angles, yet the paper will focus on the geographical and social aspect, as well as on the text's construction ${ }^{23}$.

If one focuses on the direction of the diaspora, the Dominican Republic may be treated as a periphery - the Dominican Republic is the country that people leave in order to get to the United States and look for a better life. Also, in terms of importance and wealth, the Dominican Republic may be considered peripheral to the United States. This, in turn, translates into the Dominicans' feeling of interiority. It manifests itself, for instance, in the way Oscar welcomed Yunior in the dorm: "Hail, Dog of God, was how he welcomed me my first day in Demarest. Took a week before I figured out what the hell he meant. God. Domini. Dog. Canis. Hail, Dominicanis" (BWLOW 171).

It should be noted, however, that although the Dominican Republic and Dominicans seem to be peripheral, they are the main protagonists of the story. What is more, the meaning of the Dominican Republic for Oscar upsets this simple center - periphery division. The reader learns about Oscar's feelings towards the Dominican Republic from the following fragments: "In Santo Domingo, the Land He Loved Best (what Oscar, at the end, would call the Ground Zero of the New World)" (BWLOW 1), and "Santo Domingo will always be there. It was there in the beginning and it will be there at the end" (BWLOW

\footnotetext{
${ }^{23}$ The author has conducted an in-depth analysis of the relations between the center and the peripheries in the article "Rola i znaczenie peryferii w powieści Junota Díaza Krótki i niezwykly żywot Oscara Wao" (Inne Bębny: Różnica i niezgoda w literaturze i kulturze amerykańskiej, UMCS, 2013).
} 
Neobaroque and the experience of America in The Brief Wondrous.. 133

210). These quotations amply illustrate the importance of the Dominican Republic for Oscar.

Another angle that could be adopted in the discussion of the center and the peripheries is the social one. Oscar - a Gordo and a weirdo weighing 307 pounds ( $B W L O W 173$ ) - is rejected by both Dominicans and Americans, hence becomes a periphery. The readers learn:

Oscar was a social introvert who trembled with fear during gym class and watched nerd British shows like Doctor Who and Blake's 7, and could tell you the difference between a Veritech fighter and a Zentraedi walker, and he used a lot of huge sounding nerd words like indefatigable and ubiquitous when talking to niggers who would barely graduate from high school. (BWLOW 22)

What is more, he is neither Dominican nor American enough, and he does not belong to either of the groups because of his intelligence, interests, or skin color. The narrator states that

[t]he white kids looked at his black skin and his afro and treated him with inhuman cheeriness. The kids of color, upon hearing him speak and seeing him move his body, shook their heads. You're not Dominican. And he said, over and over again, But I am. Soy dominicano. Dominicano soy. (BWLOW 49)

Despite this rejection, Oscar becomes the central character and the focal point of the novel.

The peripheries and the center may be also analyzed on the level of the construction of the text, for instance in the relation between the main body of the text and the footnotes. The copious footnotes may be treated as a periphery because of their location below the main text; yet the footnotes containing valuable pieces of information concerning the history and culture of the Dominican Republic turn out to be essential for the novel. Moreover, the footnotes are distinguished from the main text, which attaches importance to them and hence upsets the assumed center-periphery division.

The examples mentioned above demonstrate that the center and the peripheries elude easy divisions and classifications; they are not fixed but they constantly renegotiate their positions. This constant process of renegotiation may further emphasize the immigrants' experience of America and the struggle of the Dominican Americans to find their own place and develop the new identity. 
Another feature that characterizes both neobaroque and the immigrant identity is hybridity. It occurs when at least two systems (cultures, languages or traditions) meet. Since The Brief Wondrous Life of Oscar Wao is a story about Dominican Americans, it offers a whole array of examples. Hybridity is best visible on the linguistic level (and it is typical of the works of most immigrant writers). The author frequently combines English and Spanish lexical items, for example: "Abuela snorted. Guapa soy yo. Your mother was a diosa. But so cabeza dura" ( $B W L O W 75)$. Regarding the language, one may also investigate the erudite phrases coexisting with the simple language or profanities introduced to a regular language.

Hybridity in Díaz's novel is also achieved through the incorporation of science fictional elements that can be found on different levels: tropes, characters, imagery, as well as direct science fiction references. The latter can be seen in the following fragment discussing Oscar's interests:

Oscar had always been a young nerd — the kind of kid who read Tom Swift, who loved comic books and watched Ultraman - but by high school his commitment to the Genres had become absolute ... he was gorging himself on a steady stream of Lovecraft, Wells, Burroughs, Howard, Alexander, Herbert, Asimov, Bova, and Heinlein, and even the Old Ones who were already beginning to fade - E. E. "Doc" Smith, Stapledon, and the guy who wrote all the Doc Savage books moving hungrily from book to book, author to author, age to age. (It was his good fortune that the libraries of Paterson were so underfunded that they still kept a lot of the previous generation's nerdery in circulation.) You couldn't have torn him away from any movie or TV show or cartoon where there were monsters or spaceships or mutants or doomsday devices or destinies or magic or evil villains. (BWLOW 20-21)

Interestingly, also Oscar himself is referred to in science fiction terms; the narrator, for instance, says that Oscar had "finally repaired his ion drive; the evil planet Gordo was pulling him back ... Behold our cosmic explorer: eyes wide, lashed to his acceleration couch, hand over his mutant heart" (BWLOW 271). Moreover, at one point he is called a planet: "Look, Mom, that guy's taking his planet out for a run" (BWLOW 177). Apart from the introduction of hybridity, the fact that Oscar is described in sci-fi terms may serve as a comment upon 
Neobaroque and the experience of America in The Brief Wondrous.. 135

the situation of the minorities who are treated as aliens, as the Other. It may be concluded that science fiction, apart from its contribution to hybridity, serves to articulate the strange experience of exile and the migrant condition that are impossible to articulate in any other way.

What cannot be overlooked in the discussion of hybridity is the issue of intertextuality that seems to be omnipresent in the novel. The first reference to another text is found already in the title that bears resemblance to The Short Happy Life of Francis Macomber by Hemingway. Also the two mottos introduce intertextuality - the first has been taken from the comic book The Fantastic Four, and the second from Walcott's "The Schooner Flight." However, the entire text is peppered with references to other texts of culture, books, movies, computer games, TV series, including The Bible, Miracleman, Matrix, Doctor Who, Zardoz, In the Time of the Butterflies and The Sound of Music. Some of the references are direct, for instance:

I know I've thrown a lot of fantasy and sci-fi in the mix but this is supposed to be a true account of the Brief Wondrous Life of Oscar Wao. Can't we believe that an Ybón can exist and that a brother like Oscar might be due a little luck after twenty-three years? This is your chance. If blue pill, continue. If red pill, return to the Matrix" (BWLOW 285)

Other references are less obvious, like the allusions to The Lord of the Rings that require some in-depth knowledge of Tolkien's trilogy, for example "his Witchking of Angmar" (BWLOW 120).

The novel incorporates also different genres, for instance the definition of mongoose that resembles an encyclopedia entry and reads as follows:

The Mongoose, one of the great unstable particles of the Universe and also one of its greatest travelers. Accompanied humanity out of Africa and after a long furlough in India jumped ship to the other India, a.k.a. the Caribbean. Since its earliest appearance in the written record - 675 B.C.E., in a nameless scribe's letter to Ashurbanipal's father, Esarhaddon - the Mongoose has proven itself to be an enemy of kingly chariots, chains, and hierarchies. Believed to be an ally of Man. Many Watchers suspect that the Mongoose arrived to our world from another, but to date no evidence of such a migration has been unearthed. (BWLOW 151) 
The reader encounters also fragments of letters, press clippings, fragments of diaries and many more. The article offers merely a small selection of examples, yet they illustrate the scope of the references from both cultures and traditions that Díaz incorporated into his novel. The references perform also another function - they may be read as the reflections of the migrant condition: the introduction of the wellknown cultural elements brings the text closer to the reader; the inclusion of foreign words and cultural elements, however, evokes the feeling of defamiliarization. Such a strategy is employed to emphasize the confusion and exclusion experienced by the minorities in the new country.

The neobaroque elements discussed above constitute only a mere fraction of what the novel offers. I would argue, however, that such a selection is sufficient to present neobaroque as a potent tool for the discussion of the migrants' experience of the United States. Migrants' hybrid identities that constitute a mixture of cultures and languages find their reflection in the neobaroque esthetics - neobaroque is just like the immigrant experience of America; it embraces hybridity, inbetweenness, focuses on the process, not on the final effect, it crosses social and geographical borders, and gives voice to the silent groups. The employment of neobaroque strengthens the immigrant experience and allows for the articulation of what cannot be articulated in any other way. Moreover, the analytical tool offered in this article can be applied not only to the works of writers from the Dominican Republic or the Caribbean, but to a large body of immigrant literature.

\section{Bibliography}

Díaz, J. 2007. The Brief Wondrous Life of Oscar Wao. New York: Riverhead Books.

Egginton, W. 2010. The Theater of Truth: The Ideology of (Neo)Baroque Aesthetics. Stanford: Stanford University Press.

Hall, S. 1990. Cultural identity and iaspora. In: J. Rutherford (ed.), Identity: Community, Culture, Difference. London: Lawrence \& Wishart, 222-237.

Kaup, M. 2012. Neobaroque in the Americas: Alternative Modernities in Literature, Visual Art, and Film. Charlottesville: University of Virginia Press. 
Neobaroque and the experience of America in The Brief Wondrous.. 137

Krumrey, D. 2010. Translocality in the new post-American immigrant literature. In: J. Datema, D. Krumrey (eds.), Wretched Refuge: Immigrants and Itinerants in the Postmodern. Newcastle: Cambridge Scholars Publishing, 27-40.

Maver, I. 2009. Diasporic Subjectivity and Cultural Brokering in Contemporary PostColonial Literatures. New York: Lexington Books.

Ndalianis, A. 2004. (Neo)Baroque Aesthetics and Contemporary Entertainment. Cambridge: MIT Press.

Riofrio, J. 2008. Situating Latin American masculinity: Immigration, empathy and emasculation in Junot Díaz's Drown. ATENEA, 28(1), 23-36.

Salgado, C. A. 1999. Hybridity in New World Baroque Theory. The Journal of American Folklore, 112(445), 316-331.

Sarduy, S. 2010. The Baroque and the Neobaroque. In: L. Parkinson Zamora, M. Kaup (eds.), Baroque New Worlds: Representation, Transculturation, Counterconquest, Durham: Duke University Press, 270-291. 